\title{
Optimasi Pendistribusian Kelas Pada Dosen di STMIK STIKOM Indonesia Menggunakan Algoritma Genetika
}

\author{
Aniek Suryanti Kusuma*1, Komang Sri Aryati ${ }^{2}$ \\ ${ }^{1,2}$ Teknik Informatika, STMIK STIKOM Indonesia, Bali, Indonesia

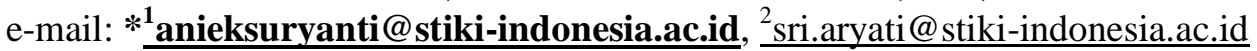

\begin{abstract}
Abstrak
Tahapan penjadwalan kelas dimulai dari menjadwalkan matakuliah didalam kelaskelas, kemudian mendistribusikan kelas tersebut kepada dosen. Proses pendistribusin kelas kepada dosen menjadi kendala badan akademik STMIK STIKOM Indonesia karena badan akademik harus menyesuaikan kelas yang ada dengan dosen yang meminatinya serta dosen yang dipilih untuk mengampu suatu kelas agar tidak mempunyai kelas yang memiliki bentrok waktu.

Salah satu metode untuk menyelesaikan permasalahan tersebut dengan menggunakan algoritma genetika yang bekerja dengan membangkitkan sejumlah solusi random kemudian mengolah kumpulan solusi tersebut dalam sebuah proses genetika. Terdapat delapan prosedur algoritma genetika yaitu prosedur pembangkitan kromosom secara acak (random), repair kromosom untuk memvalidasi kromosom dari batasan yang dimiliki, fungsi fitness untuk menghitung nilai kelayakan dari suatu solusi, crossover, mutasi, repair anak dan elitisme.

Hasil output dari penelitian ini berupa analisis dan penentuan kebutuhan sistem yang harus ada. Selain itu, menghasilkan laporan uji coba pengaruh parameter genetika untuk mengetahui pengaruh perubahan nilai parameter genetika terhadap nilai fitness dan waktu yang digunakan untuk melakukan proses pendistribusian.
\end{abstract}

Kata kunci-Sistem Penjadwalan, Algoritma Genetika, Artificial Intelligence.

Abstract

The stage of class scheduling starts from scheduling courses in classes, then distributing the class to lecturers. The process of distributing classes to lecturers becomes an obstacle for the STMIK STIKOM Indonesia academic body because the academic body must adjust the existing class with the lecturer who is interested in it as well as the lecturer chosen to support a class so that it does not have classes that have a time conflict.

One method for solving these problems is by using genetic algorithms that work by generating a number of random solutions and then processing the collection of solutions in a genetic process. There are eight genetic algorithm procedures, which are random chromosome generation procedures, chromosome repair to validate chromosomes from their limits, fitness function to calculate the feasibility of a solution, crossover, mutation, child repair and elitism.

The output of this research is in the form of an analysis and determination of the system requirements that must exist. In addition, it produces a trial report on the effect of genetic parameters to determine the effect of changes in the value of genetic parameters on the fitness value and the time used to carry out the distribution process.

Keywords - Scheduling System, Genetic Algorithms, Artificial Intelligence.

Received August $3^{\text {rd }}$, 2019; Revised September 17 ${ }^{\text {th }}$ 2019; Accepted September $26^{\text {th }}$, 2019 


\section{PENDAHULUAN}

STMIK STIKOM Indonesia merupakan salah satu perguruan tinggi yang menjadwalkan kegiatan perkuliahan mahasiswanya didalam sebuah jadwal kelas. Proses penjadwalan kelas di STMIK STIKOM Indonesia masih dilakukan dengan penyusunan manual. STMIK STIKOM Indonesia sampai sekarang masih mengandalkan kecermatan pegawai bagian akademik untuk melakukan proses penjadwalan kelas dengan menggunakan software Microsoft Excel. Penelitian sebelumnya yg membuat sistem informasi penentuan kelas unggul dengan k-means [1], sistem informasi juga dapat digunakan dalam pembuatan e-government [2]. Pengembangan sistem informasi juga dapat digunakan untuk penetuan keputusan pada sistem pendukung keputusan [3] dan penerapan pada sistem informasi geografis [4].

Proses penjadwalan kelas yang dilakukan oleh STMIK STIKOM Indonesia terdiri dari dua proses yaitu yang pertama ialah penjadwalan kelas- kelas matakuliah tanpa dosen, yang kedua adalah kelas-kelas yang telah dibuat sebelumnya didistribusikan kepada dosen. Dari kedua proses tersebut, proses yang paling menjadi kendala bagi badan akademik adalah proses yang kedua. Dalam proses pendistribusian kelas pihak badan akademik harus mendistribusikan kelas sesuai dengan angket matakuliah yang diisi dosen. Angket matakuliah tersebut berisi batasan kelas-kelas mana saja yang mampu diambil dosen. Proses pendistribusian kelas ini menjadi kendala karena selain proses ini masih dilakukan manual, badan akademik harus cermat untuk mencari dan menentukan kelas yang sesuai dengan angket matakuliah yang telah diisi dosen. Sebelum penelitian ini dilakukan, konfigurasi access point dilakukan secara manual pada setiap access point yang ada, konfigurasi yang dilakukan adalah mengatur user dan password yang digunakan untuk koneksi ke access point, mendaftarkan mac address dari setiap perangkat yang akan digunakan, mengatur SSID yang akan digunakan pada setiap network yang akan dilayani oleh access point. Kendala yang dihadapi dengan konfigurasi secara manual ini adalah repotnya proses konfigurasi yang harus dilakukan pada setiap titik access point, setiap pengguna mengeluhkan proses login yang berulangkali harus dilakukan ketika berpindah tempat sehingga harus berpindah access point yang digunakan.

\section{METODE PENELITIAN}

Penjadwalan merupakan pengalokasian sejumlah subjek kedalam periode tertentu, sedemikian hingga dapat memenuhi sebanyak mungkin batasan-batasan yang diberikan. Optimasi merupakan suatu teknik pendekatan normatif untuk mengidedtifikasikan penyelesain terbaik dari suatu permasalahan untuk membantu pengambilan keputusan. Penyelesaian masalah dengan teknik optimasi diarahkan untuk mendapatkan titik maksimum atau minimum dari fungsi yang ingin dioptimasi. Tujuan dari optimasi adalah meminimumkan usaha/biaya operasional dan memaksimumkan hasil yang diinginkan. Algoritma genetika (AG) merupakan sebuah algoritma pencarian yang didasarkan pada mekanisme seleksi ilmiah dan genetika ilmiah [5]. Sesuai dengan pengertiannya, istilah-istilah yang ada pada Algoritma genetika sama dengan istilah-istilah pada evolusi biologi [5]. Basis Data (database) merupakan kumpulan data yang terorganisasi dari data-data yang secara nalar terkait [6,7]. Sebuah database mencatat berbagai data yang diperlukan oleh suatu organisasi. Data Flow Diagram (DFD) memperlihatkan gambaran tentang masukan-proses-keluaran dari suatu sistem/perangkat lunak yaitu, objekobjek data mengalir ke dalam perangkat lunak, kemudian objek-objek data itu akan di transformasi oleh elemen - elemen pemrosesan, dan objek - objek data hasilnya akan mengalir keluar dari sistem/perangkat lunak [8-10].

Metode pengumpulan data yang dilakukan pada penelitian ini adalah metode pengumpulan data primer yaitu melalui wawancara dan Observasi. Metode wawancara ini dilakukan dengan

JSIKTI Vol. 2, No. 1, September 2019: $11-20$ 
cara tanya jawab dengan Pembantu Ketua I STMIK STIKOM Indonesia untuk mengetahui batasan yang perlu dipertimbangkan dalam pendistribusian kelas pada dosen serta hal - hal lainya yang terkait dengan sistem pendistribusian kelas yang dilakukan STMIK STIKOM Indonesa. Observasi dilakukan untuk mengamati bagaimana proses pendistribusian kelas pada dosen yang dilakukan oleh STMIK STIKOM Indonesia.

\subsection{Analisis Data}

Penjadwalan kelas mata kuliah di STMIK STIKOM Indonesia dilakukan oleh badan akademik dengan cara manual menggunakan Microsoft Excel. Setelah jadwal kelas mata kuliah selesai dijadwalkan, data jadwal dimasukan kedalam sistem angket mata kuliah yang sudah ada, untuk nantinya dipilih oleh dosen. Dalam kebijakan mengisi angket mata kuliah, Badan Akademik memperbolehkan dosen untuk bebas memilih kelas mana yang diminati untuk diampu, karena hasil dari angket mata kuliah bukanlah hasil akhir dari proses pendistribusian kelas. Kebebasan dosen memilih kelas pada angket mata kuliah, memungkinan dosen memilih banyak kelas dan kelas-kelas tersebut memiliki kemungkinan bentrok waktu dengan kelas-kelas lain yang telah dipilih dosen tersebut. Hasil angket mata kuliah dapat dilihat pada Tabel 1.

Tabel 1 Contoh Hasil Angket Mata Kuliah

\begin{tabular}{|c|c|c|c|c|c|c|}
\hline Kode_Kelas & Kode_MK & Kelas & Jam & Hari & Ruang & Kode_Dosen \\
\hline KLS1 & MK01 & A & $12.45-15.00$ & Senin & 201 & D01 \\
\hline KLS1 & MK01 & A & $12.45-15.00$ & Senin & 201 & D02 \\
\hline KLS1 & MK01 & A & $12.45-15.00$ & Senin & 201 & D03 \\
\hline KLS2 & MK02 & C & $9.00-11.15$ & Jumat & 202 & D02 \\
\hline KLS2 & MK02 & C & $9.00-11.15$ & Jumat & 202 & D04 \\
\hline KLS3 & MK02 & B & $7.30-9.45$ & Kamis & 203 & D03 \\
\hline KLS4 & MK03 & D & $9.00-11.45$ & Jumat & 204 & D01 \\
\hline KLS4 & MK03 & D & $9.00-11.45$ & Jumat & 204 & D04 \\
\hline
\end{tabular}

Dapat dilihat pada tabel hasil angket mata kuliah diatas, terdapat kelas yang berulang. Contohnya kelas dengan kode KLS1 kelas ini berulang sampai 3 kali namun dosennya berbedabeda. Hal ini menunjukan KLS01 memiliki 3 dosen yang meminati kelas tersebut.

Hasil angket mata kuliah tersebut kemudian digunakan oleh Pembantu Ketua I (PK I) STMIK STIKOM Indonesia sebagai acuan untuk mendistribusikan kelas kepada dosen. PK I memilih dosen yang akan mengampu kelas-kelas sesuai dengan dosen yang meminati kelas tersebut dalam hasil angket mata kuliah. Kelas-kelas didistribusikan kepada dosen agar sebisa mungkin jumlah SKS kelas yang diampu masing-masing dosen sesuai dengan batasan yang ditentukan badan akademik dan memperkecil jumlah kelas yang tidak mendapatkan dosen karena kuota SKS pada dosen yang berminat pada kelas tersebut telah penuh.

\section{2 Analisis Sistem}

Berdasarkan analisis data diatas sistem optimasi pendistribusian kelas pada dosen yang akan dibuat akan mengikuti prosedur dari penjadwalan mata kuliah yang dilakukan badan akademik STMIK STIKOM Indonesia yaitu sistem pendistribusikan kelas kepada dosen sesuai dengan angket mata kuliah. Secara umum sistem informasi optimasi pendistribusian kelas pada dosen yang akan dibuat dalam penelitian ini adalah sistem optimasi yang menerima inputan data hasil angket mata kuliah yang telah dipilih oleh dosen, kemudian diproses menggunakan metode algoritma genetika. Hasil output dari sistem optimasi ini adalah jadwal kelas yang optimal dari segi pendistribusian kelas-kelas kepada dosen-dosen yang mengisi angket matakuliah. Penelitian ini diharapkan dapat memenuhi seluruh batasan yang ada dalam hal pendistribusian kelas pada dosen. Gambaran umum dari sistem informasi optimasi pendistribusian kelas kepada dosen di STMIK STIKOM Indonesia dapat dilihat pada Gambar 1.

Optimasi Pendistribusian Kelas Pada Dosen di STMIK STIKOM... (Aniek Suryanti Kusuma) 


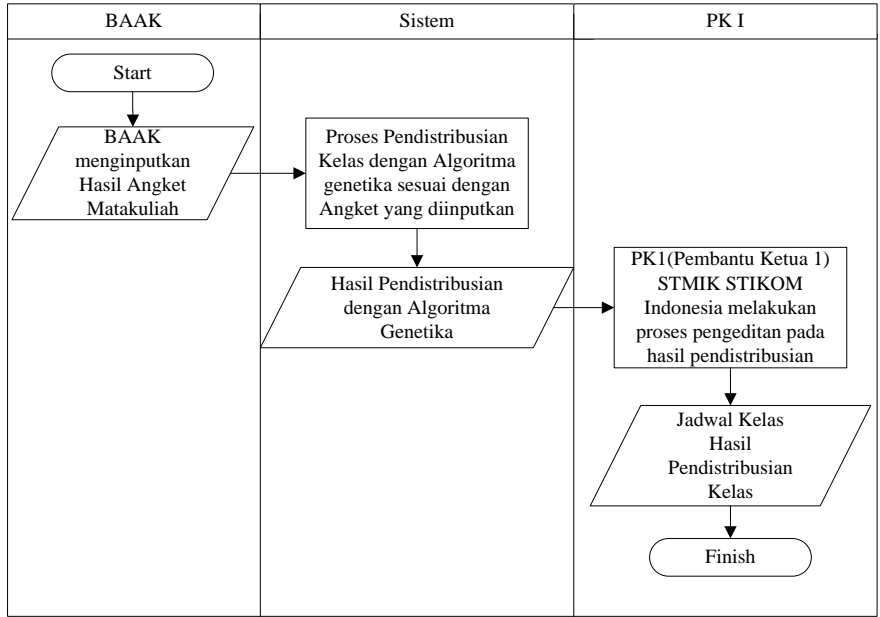

Gambar 1 Gambaran umum sistem informasi optimasi pendistribusian kelas kepada dosen

\subsection{Algoritma Genetika Dalam Sistem}

Algoritma genetika pertama membangkitkan himpunan solusi dari permasalahan yang disebut populasi. Setiap individu dalam populasi disebut kromosom yang merupakan representasi dari solusi dari permasalahan. Masing-masing kromosom akan dievaluasi tingkat ketanggguhannya (fitness) oleh fungsi yang telah ditentukan. Melalui proses seleksi alam atas operator genetik, gen-gen dari dua kromosom (disebut parent) diharapkan akan menghasilkan kromosom baru dengan tingkat fitness yang lebih tinggi sebagai generasi baru atau keturunan (offspring) berikutnya.

Secara umum tahap-tahap algoritma genetika yang dilakukan untuk menyelesaikan permasalahan pendistribusian kelas pada dosen dalam penelitian ini dapat dilihat pada diagram alir pada Gambar 2 .

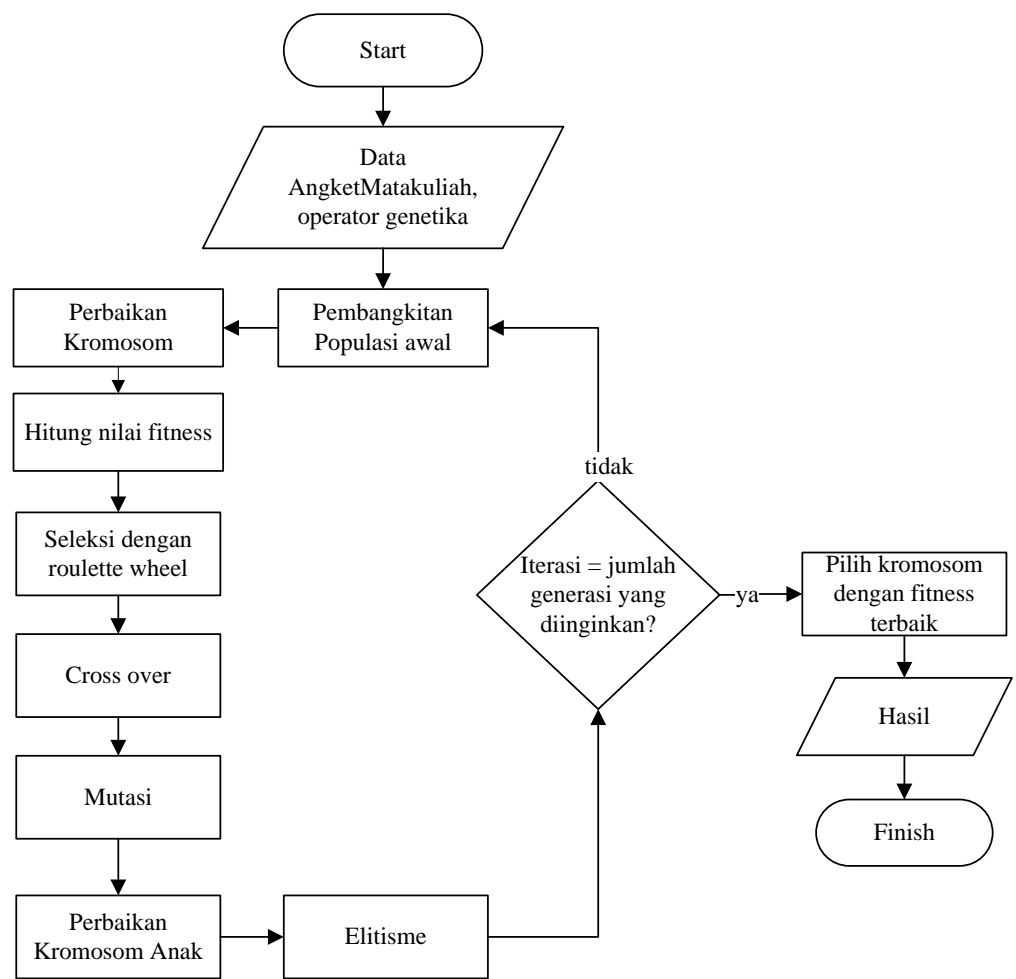

Gambar 2 Flowchart Algoritma Genetika pada Sistem 


\section{HASIL DAN PEMBAHASAN}

\subsection{Diagram Konteks}

Gambar 3 merupakan diagram konteks dari Sistem Informasi Optimasi Pendistribusian Kelas kepada Dosen. Terdapat dua entitas yang berhubungan dengan sistem ini yaitu BAAK dan PK I. BAAK dapat menambah list angket, mencari list angket, mengubah list angket, menambah detail angket, mencari detail angket, menginputkan data list angket untuk laporan. Sementara PK I dapat mendistribusikan dan mengedit hasil pendistribusian kelas. Hasil output dari sistem berupa Hasil Pendistribusian dan Hasil Edit Pendistribusian mengalir ke-PK I. Sementara BAAK mendapatkan output berupa List dan Detail Angket serta Laporan Hasil Pendistribusian dan Laporan Hasil Edit Pendistribusian.

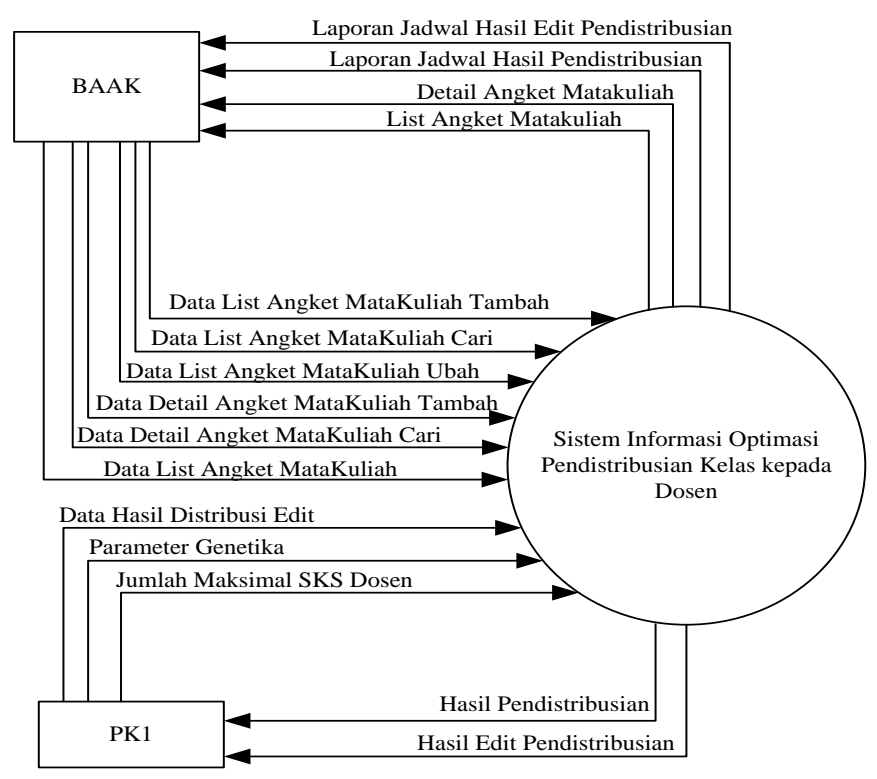

Gambar 3 Diagram Konteks Sistem Informasi Optimasi Pendistribusian Kelas kepada Dosen

\subsection{DFD Level 0}

Data flow diagram level 0 pada Gambar 4 terlihat ada tiga proses utama yang dapat dilakukan dalam sistem ini. Proses pertama yaitu mengelola angket mata kuliah yang dapat dilakukan oleh BAAK hasil proses tersebut disimpan pada dua simpanan data yaitu D1 List Angket Mata Kuliah untuk menyimpan list angket mata kuliah, dan D2 Detail Angket Mata Kuliah untuk menyimpan detail dari setiap list angket mata kuliah. Proses kedua yaitu pendistribusian kelas, proses ini dilakukan oleh PK I dan hasilnya disimpan pada simpanan data D3 Hasil Pendistribusian dan hasil editnya disimpan pada D4 Hasil Edit Pendistribusian. Proses ketiga adalah pelaporan jadwal kelas yang dapat dilakukan oleh BAAK dengan informasi yang diambil dari D3 Hasil Pendistribusian dan D4 Hasil Edit Pendistribusian.

\subsection{Entity Relationship Diagram}

Gambar 5 menunjukkan hubungan antara entitas yang ada dalam Sistem Pendistribusian Kelas. Terdapat empat entitas dalam diagram diatas yaitu List Angket Matakuliah, Detail Angket Matakuliah, Hasil Pendistribusian, dan Hasil Edit Pendistribusian. Entitas List Angket_Matakuliah berhubungan one to many kepada ketiga entitas lainnya, sehingga primary key pada entitas List Angket Matakuliah menjadi foreign key di tiga entitas lainnya. 


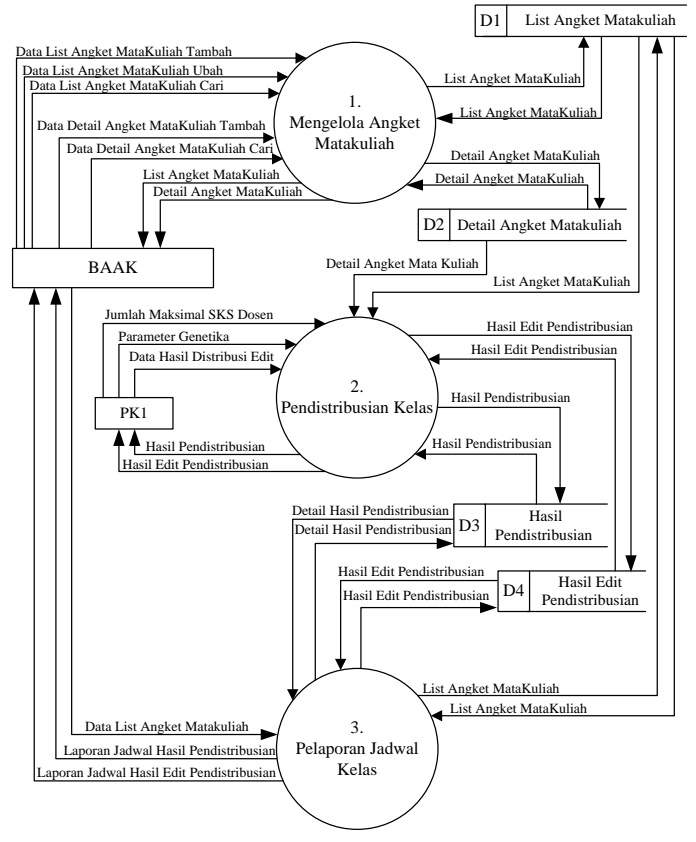

Gambar 4 DFD Level 0

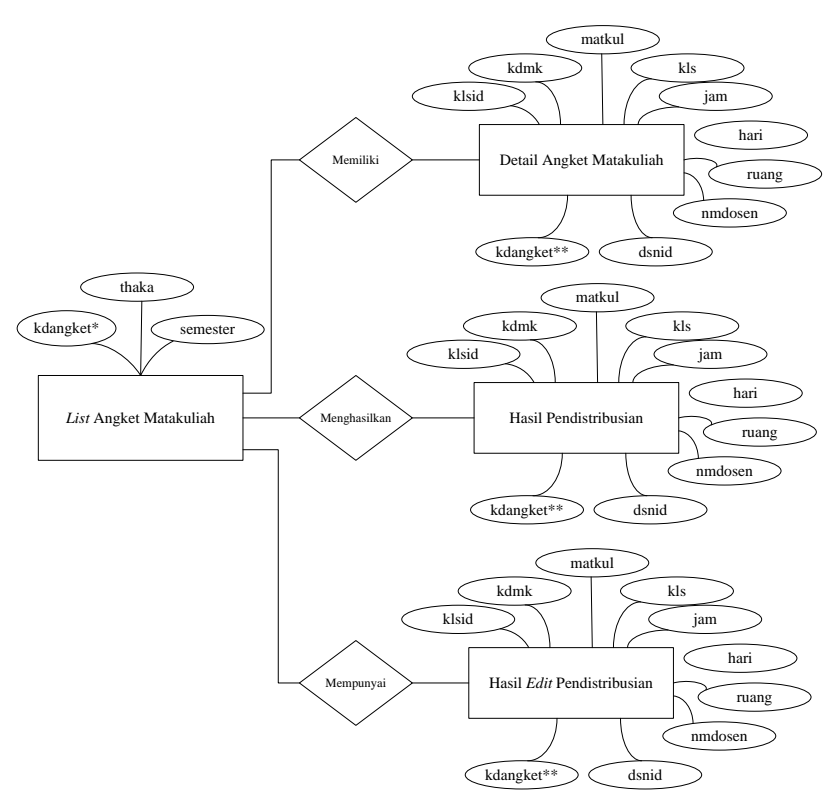

Keterangan:

$$
\begin{aligned}
& *=\text { Primari key } \\
& * *=\text { Foreign key }
\end{aligned}
$$

Gambar 5 ERD dalam Sistem Pendistribusian Kelas

\subsection{System Spesification}

Dalam Sistem Spesification ini berisi rancangan interface yang terdapat dalam Sistem Informasi Optimasi Pendistribusian Kelas Kepada Dosen di STMIK STIKOM Indonesia. 


\section{a. Form Utama}

Form pada Gambar 6 merupakan form awal yang muncul ketika program dijalankan. Form ini berisi 3 menu pilihan yaitu Kelola Angket, Pendistribusian, dan Laporan.

\section{b. Form List Angket}

Form list Angket pada Gambar 7 akan muncul jika menu List Angket di klik. Form ini digunakan untuk mengelola List Angket, disini pengguna dapat menambah, mengubah dan mencari list angket. Tersedia juga kolom untuk tombol edit untuk mengedit list angket dan tombol lihat untuk melihat detail angket.

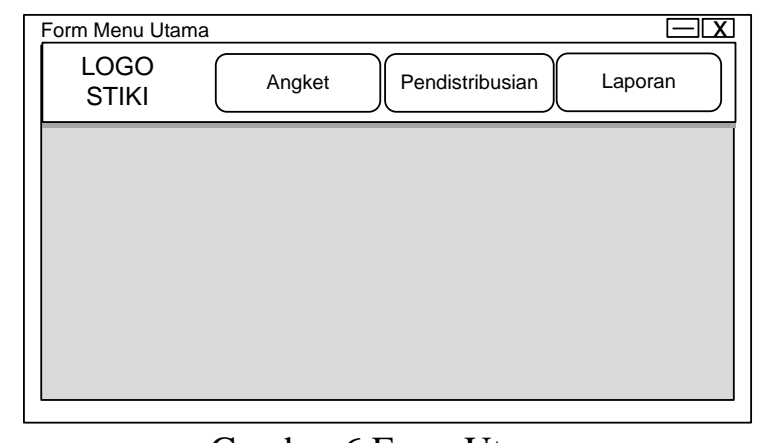

Gambar 6 Form Utama

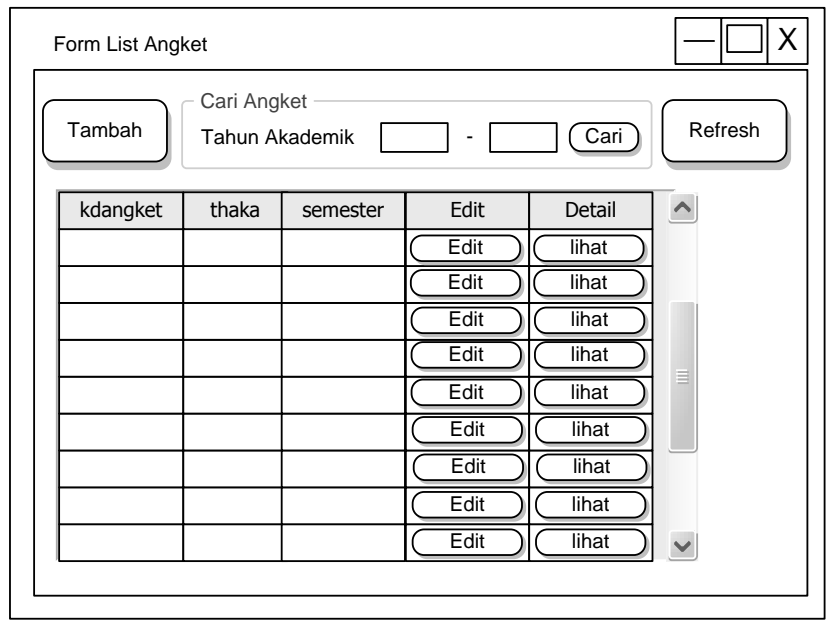

Gambar 7 Form List Angket

\section{c. Form Pendistribusian}

Form Pendistribusian pada Gambar 8 muncul setelah pengguna memilih tombol Pendistribusian pada Form Menu Utama. Didalam Form ini terdapat dua buah data grid. Data grid sebelah kiri digunakan untuk memilih angket yang belum didistribusikan untuk didistribusikan. Data grid di sebelah kanan digunakan untuk melihat hasil pendistribusian dengan algoritma genetika dan mengedit hasil pendistribuian.

\section{d. Form Laporan}

Form Laporan pada Gambar 9 diatas muncul saat menu Laporan pada Form Menu Utama dipilih. Form ini digunakan untuk membuat laporan dari hasil pendistribusian kelas berdasarkan hangket mata kuliah yang dipilih. Terdapat hasil pendistribusian yang dapat 
dilaporkan, yaitu Hasil Pendistribusian menggunakan algoritma genetika, atau Hasil Edit Pendistribusian tersebut.

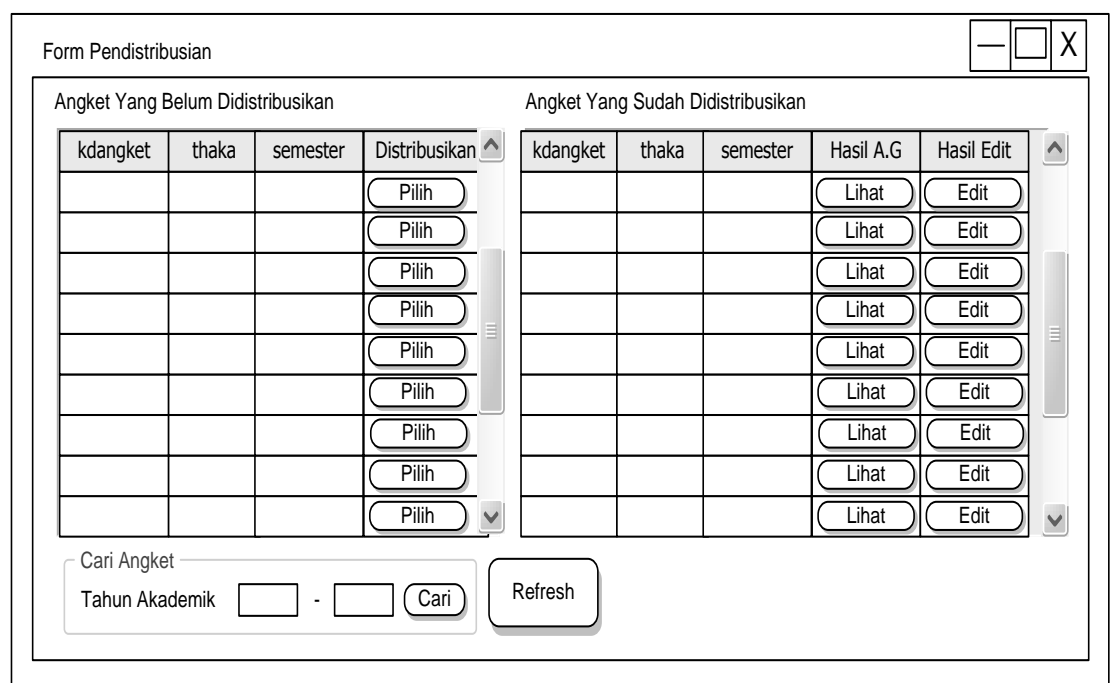

Gambar 8 Form Pendistribusian

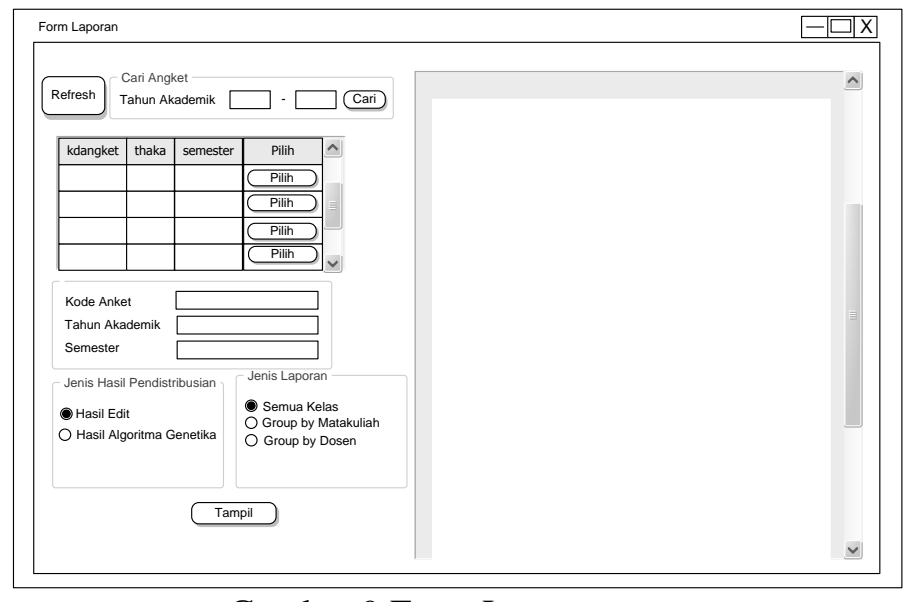

Gambar 9 Form Laporan

\section{KESIMPULAN}

Berdasarkan hasil dan uraian pembahasan di atas maka dapat disimpulkan bahwa dalam pembangunan sistem informasi diperlukan sebuah analisis sistem, perancangan sistem, kemampuan dalam mengimplementasikan hasil rancangan sistem dengan mengaplikasikan bahasa pemograman dan pembangunan sistem database, serta melakukan pengujian terhadap implementasi sistem tersebut. Pembangunan sistem informasi pendistribusian kelas pada dosen di STMIK STIKOM Indonesia dengan menggunakan algoritma genetika, merupakan solusi dapat menyelesaikan permasalahan.

Berikut beberapa kesimpulan yang didapat dari penelitian pembangunan sistem informasi pendistribusian kelas pada dosen di STMIK STIKOM Indonesia menggunakan algoritma genetika yaitu, Algoritma genetika pada proses pendistribusian kelas menjadi lebih cepat dari 
proses penjadwalan sebelumnya, sehingga pembuatan pendistribusaian kuliah tidak melebihi tenggang waktu yang telah ditentukan dan tidak menghambat sistem operasional perkuliahan. Pada sistem informasi yang dibangun, penyebaran informasi jadwal kuliah terhadap dosen dan mahasiswa menjadi lebih cepat, dikarenakan adanya pemanfaatan media teknologi informasi.

\section{SARAN}

Pembanguanan sistem informasi pendistribusian kelas pada dosen di STMIK STIKOM Indonesia menggunakan algoritma genetika terdapat beberapa kekurangan, karena kebutuhan dan fungsi terus bertambah. Selain itu ada beberapa permasalahan serta kebutuhan yang belum terselesaikan pada penelitian ini yaitu pertama, adanya percobaan penggunakan teknik lain pada operator seleksi, crossover dan mutasi. Hal tersebut untuk membandingkan penggunaan teknik pada setiap operator sehingga ditemukan teknik yang paling optimal. Kedua, dibuatkan fasilitas untuk mengubah (menambah atau mengurangi) constraint pendistribusian kelas supaya dapat disesuaikan dengan kebutuhan yang ada. Ketiga, sistem informasi yang dibangun dapat terintegrasi dengan sistem lain yang sudah ada di STMIK STIKOM Indonesia.

\section{UCAPAN TERIMA KASIH}

Pada kesempatan ini penulis menyampaikan rasa terima kasih yang sebesar-besarnya dan penghargaan yang setinggi-tingginya kepada STMIK STIKOM Indonesia atas pendanaan penelitian dengan skema Penelitian Pengembangan Dosen tahun anggaran 2019.

\section{DAFTAR PUSTAKA}

[1] A. Kusuma and K. Aryati, "Sistem Informasi Akademik Serta Penentuan Kelas Unggulan Dengan Algoritama K-Means di SMP Negeri 3 Ubud", jsikti, vol. 1, no. 3, pp. 143-152, Mar. 2019.

[2] P.Sugiartawan,I.D.K.R. Rustina, R.W.S. Insani, "E-Government Media Informasi Alat Kelengkapan Dewan Provinsi Bali dan Media Diskusi Berbasis Website," J. Sist. Inf. dan Komput. Terap. Indones., vol. 2, no. 1, 2018.

[3] I. Pratistha, P. Sugiartawan, U. G. Mada, M. Manajemen, and U. G. Mada, "Sistem Pendukung Keputusan Kelompok Pemilihan E-Commerrce Menggunakan Metode Profile Matching dan BORDA," vol. 1, no. 1, 2018.A. Mauko, B. Muslimin, and P. Sugiartawan, ìSistem Pendukung Keputusan Kelompok Dalam Pemilihan Saham Indeks LQ 45 Menggunakan Metode," J. Sist. Inf. dan Komput. Terap. Indones., vol. 1, no. 1, pp. 25-34, 2018.

[4] D. Dwi Utami Putra and P. Sugiartawan, "Sistem Informasi Geografis Tata Guna Lahan di Kabupaten Sleman”, jsikti, vol. 1, no. 3, pp. 175-184, Mar. 2019.

[5] Z. Zukhri, "Algoritma Genetika Metode Komputasi Evolusioner untuk Menyelesaikan Masalah Optimasi, Yogyakarta: ANDI, 2014.

[6] A. Kadir,"Dasar Perancangan dan Implementasi Database Resaional”, Yoyakarta: Andi, 2009.

[7] Fathansyah, "Basis Data", Bandung: Informatika, 2012.

[8] R.S. Pressman, "Rekayasa Perangkat Lunak Pendekatan Praktisi", Yogyakarta:Andi, 2012

[9] S. T, E. Mulyanto and D. Suhartono, "Kecerdasan Buatan," Yogyakarta: ANDI, 2011. 
[10] R.A.S and M. Shalahudin, "Rekayasa Perangkat Lunak: Terstruktur dan Berorientasi Objek," Bandung: Informatika, 2013. 